\title{
MATHEMATICAL SIMULATION AND MEASUREMENT OF EXPANSION OF HYDRAULIC HOSE WITH OIL
}

\author{
Lumír Hružík, Adam Bureček, Martin Vašina
}

Preliminary communication

The paper deals with measurement and mathematical simulation of expansion of a hydraulic hose including the effect of oil bulk modulus. Young's modulus of elasticity of the hydraulic hose is experimentally determined by expansion method and by compression method. The modulus of elasticity of the hydraulic hose obtained from the expansion method is determined by measurement of an oil volumetric gain, which is compressed inside the investigated hose after the oil expansion. The Young's modulus of elasticity of the hydraulic hose obtained from the compression method is determined by measurement of oil flow and pressure increase vs. time in the hydraulic hose. The oil bulk modulus is experimentally determined by means of the expansion method and the method of oil compression in a steel pipe. A hydraulic circuit for simulation of the oil expansion from the hose and the steel pipe was created using Matlab SimHydraulics software. The oil volume increase after the expansion from the hydraulic hose and the steel pipe was numerically simulated. Furthermore, time dependencies of pressure decreases during the oil expansion from the hydraulic hose and the steel pipe were numerically simulated. Results of the mathematical simulations were compared with the experiment while using the Young's modulus of elasticity of the hose and the oil bulk modulus that were determined by the expansion method and by the compression method.

Keywords: air bubbles; bulk modulus; compression; expansion; hydraulic hose; mathematical simulation; oil; Young's modulus of elasticity

\section{Matematička simulacija i mjerenje širenja hidrauličnog crijeva s uljem}

Prethodno priopćenje

Rad se bavi mjerenjem i matematičkom simulacijom širenja hidrauličnog crijeva, uključujući učinak modula stlačivosti ulja. Youngov modul elastičnosti hidrauličnog crijeva eksperimentalno je određen metodom ekspanzije i metodom kompresije. Modul elastičnosti hidrauličnog crijeva dobiven metodom ekspanzije određen je mjerenjem povećanja volumena ulja, sabijenog u ispitivanom crijevu nakon ekspanzije. Youngov modul elastičnosti hidrauličnog crijeva, dobiven metodom kompresije, određen je mjerenjem protoka ulja i porasta tlaka u hidrauličnom crijevu u odnosu na vrijeme. Modul stlačivosti ulja eksperimentalno je određen metodom ekspanzije i metodom kompresije ulja u čeličnoj cijevi. Hidraulični krug za simulaciju širenja ulja u crijevu i čeličnoj cijevi stvoren je primjenom softvera Matlab SimHydraulics. Povećanje volumena ulja nakon širenja u hidrauličnom crijevu i čeličnoj cijevi numerički je simulirano. Nadalje, vremenske ovisnosti smanjenja tlaka tijekom širenja ulja u hidrauličnom crijevu i čeličnoj cijevi numerički su simulirane. Rezultati matematičkih simulacija uspoređeni su s eksperimentalnim tijekom primjene Youngova modula elastičnosti crijeva i modula stlačivosti ulja određenih metodom ekspanzije i metodom kompresije.

Ključne riječi: hiydraulično crijevo; kompresija; ekspanzija; matematička simulacija; modul stlačivosti; ulje; zračni mjehur; Youngov modul elastičnosti

\section{Introduction}

There are several approaches for mathematical simulation of hydraulic lines at the present time. A system of liquid and pipe or hose is considered as a hydraulic line. This paper is focused on high-pressure hydraulics. Mineral oil is the most used liquid in high-pressure hydraulics. Steel seamless pipes or rubber hoses with one or more steel braids are most often used for oil flow. During implementation of hydraulic systems, their predesign by means of mathematical simulations is increasingly taken into account. In this way, it avoids possible complications during the actual system realization. Two possible approaches to the mathematical simulation of the hydraulic line are described in this paper. These approaches differ the hydraulic oil as homogenous or multiphase substance. Furthermore they differ the pipe and the hose as solid or elastic body. These different approaches have influence especially on resultant dynamics of the mathematical model of the hydraulic system $[1,2]$. The mathematical model of oil in a hydraulic system includes its main physical properties, as is density, kinematic viscosity, bulk modulus and content of undissolved air bubbles. The oil bulk modulus is further divided into secant and tangent, as indicated in [3]. If oil is considered as the homogenous substance in the mathematical model, its compressibility is defined only by the oil bulk modulus. This bulk modulus includes the influence of undissolved air content. If the oil is considered as the multiphase substance, its compressibility is defined by means of the bulk modulus and undissolved air content, as indicated in [4-9]. This bulk modulus does not include the effect of the undissolved air content, which is separately entered. Air bubbles occur in oil in dissolved and undissolved forms [10]. Release and dissolution of air bubbles is given by the Henry's law [11]. The release of air or steam bubbles during underpressure and their subsequent compression in the high pressure region is an undesirable phenomenon, which is called cavitation $[12,13]$. The mathematical model of a stiff steel pipe or a stiff hydraulic hose is defined by their dimensions. The mathematical model of an elastic pipe or an elastic hydraulic hose is further defined by their Young's modulus of elasticity and Poisson ratio, as indicated in $[14,15]$. The Matlab SimHydraulics software was selected for the mathematical simulation of a hydraulic system due to physical access and advanced mathematical models [1619]. This software is used in order to perform the comparison of the mathematical models of oil as the homogenous substance or the multiphase substance. Furthermore the comparison is performed on the mathematical models, where the hose is defined by the Young's modulus of elasticity, which is determined by the expansion method or by the compression method. Boundary conditions, as pipe (or hose) dimensions or oil density and kinematic viscosity, can be determined relatively easily. The determination of the oil bulk 
modulus and the Young's modulus of elasticity of the hydraulic hose is already rather difficult. For this reason the determination of these boundary conditions is a part of this article.

\section{Methods for determination of oil bulk modulus and hose elastic modulus}

Two different methods for determination of the oil bulk modulus and the Young's modulus of elasticity of the hydraulic hose, namely by means of the expansion method and by the compression method, are described in this chapter.

The expansion method consists in closing oil volume in the steel pipe or the hose under a required pressure and the subsequent oil expansion. The oil bulk modulus is subsequently determined on the basis of knowledge of dimensions of the steel pipe, the Young's modulus of elasticity of the steel pipe, the pressure gradient and the oil volume increase after its expansion from the steel pipe. The Young's modulus of elasticity of the hose is determined on the basis of knowledge of their dimensions, the oil bulk modulus, the pressure gradient and the oil volume increase after its expansion from the hose. The quantities determined by the expansion method are marked by the index " 1 " in the text.

The compression method consists in measurement of the pressure increase vs. time during the oil compression in the steel pipe or the hose. It is necessary to know an exact characteristic of a pressure oil source (i.e. $\Delta p-Q$ characteristic of a hydraulic aggregate) for this method. Then it is possible to determine the oil volume increase during its compression in the steel pipe or the hose on the basis of knowledge of the actual flow $Q$ at the given pressure gradient $\Delta p$ and the compression time $\Delta t$. The quantities determined by the compression method are marked by the index " 2 " in the text.

\subsection{Description of experimental equipment}

The schematic diagram of the experimental equipment is shown in Fig. 1. The hydraulic aggregate is a source of the pressure oil and consists of the tank T, the hydraulic pump HP, the relief valve RV, the check valve $\mathrm{CV}$, the directional valve $\mathrm{V}$ and the manometer $\mathrm{M}$. Furthermore, there is the steel pipe $\mathrm{P}$, which enables to determine the oil bulk modulus. The device further allows determining the Young's modulus of elasticity $E_{H}$ of the hose $\mathrm{H}$. The oil, which is under pressure, is closed in the pipe $\mathrm{P}$ (or the hose $\mathrm{H}$ ) by means of the stop valves SV1 and SV2 (or SV3 and SV4). The oil pressure is measured by the pressure sensor PS1 in the pipe $\mathrm{P}$ and by the pressure sensor PS2 in the hose H. The stop valves SV5 and SV6 are used in order to regulate oil flow during its expansion from the pipe $\mathrm{P}$ or the hose $\mathrm{H}$ into the measuring tube MT. A change of the height level $\Delta h$ in the measuring tube MT is subsequently measured. Signals from the pressure sensors are recorded by means of the measuring equipment Hydrotechnik M5050. The maximum working pressures of the hose and the pipe are given by manufacturers. In the case of the hydraulic hose, the maximum pressure was exceeded during the measurement. The hose must be for a short term resistant to double pressure according to the test defined in ISO 1402. These hoses are damaged only after reaching the quadruple working pressure.

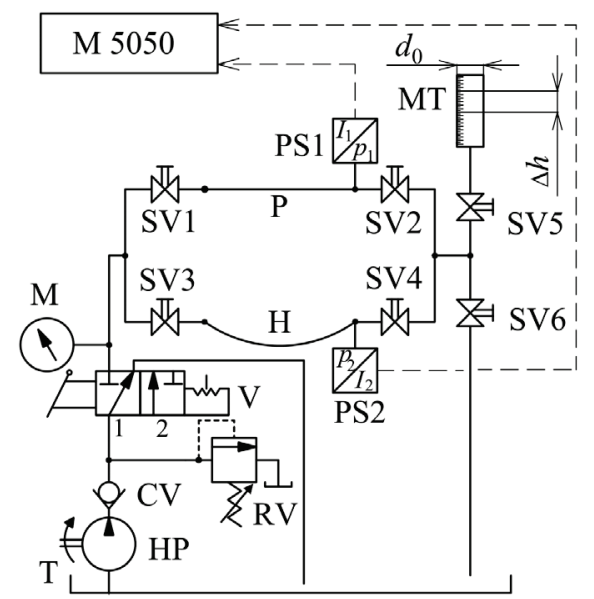

Figure 1 Schematic diagram of experimental equipment

The parameters of the pipe, the hose, the measuring tube and the oil are the following:

1) $\mathrm{P}$ - length $l_{P}=1.6 \mathrm{~m}$, outside diameter $D_{P}=0.03 \mathrm{~m}$, inside diameter $d_{P}=0.022 \mathrm{~m}$, wall thickness $s_{P}=$ $0.004 \mathrm{~m}$, Young's modulus of elasticity $E_{P}=2.1 \cdot 10^{11}$ $\mathrm{Pa}$ [20], Poisson ratio $v_{P}=0.3$ [21], maximum working pressure $p_{P, \max }=321 \mathrm{bar}$.

2) $\mathrm{H}$ - length $l_{H}=1.568 \mathrm{~m}$, outside diameter $D_{H}=0.0234 \mathrm{~m}$, inside diameter $d_{H}=0.016 \mathrm{~m}$, wall thickness $s_{H}=0.0037 \mathrm{~m}$, number of steel braids $b=1$, Poisson ratio $v_{P}=0.47$ [22], maximum working pressure $p_{H, \max }=130$ bar.

3) Measuring tube MT - inside diameter $d_{0}=0.0098$ $\mathrm{m}$.

4) Oil-OH-HM 46, oil temperature $t_{\mathrm{O}}=25^{\circ} \mathrm{C}$.

\subsection{Determination of oil bulk modulus and Young's modulus of elasticity of hose by means of expansion method}

The method of determination of the oil bulk modulus $K_{1}$ and the Young's modulus of elasticity $E_{H 1}$ of the hose consists in measurement of the oil volume increase $\Delta V_{P 1}$ after its expansion from the steel pipe $\mathrm{P}$ or the oil volume increase $\Delta V_{H 1}$ after its expansion from the hose $\mathrm{H}$. The oil volume increase $\Delta V_{P 1}$ after the expansion from the steel pipe $\mathrm{P}$ is measured in such a way that the stop valves SV1, SV3, SV4 and SV5 are closed, the stop valves SV2 and SV6 are open, the valve $\mathrm{V}$ is in the position 1 and the oil flows freely into the tank $\mathrm{T}$. The valve $\mathrm{V}$ is subsequently set to the position 2 and the required working pressure $p$ is adjusted by the relief valve RV. After opening the stop valve SV1, the oil flows through the pipe $P$ into the tank T. The stop valve SV2 is subsequently closed and the stop valve SV1 is closed after pressurization of the system to the required pressure $p$. At the same time the oil is compressed at the pressure $p$ between the valves SV1 and SV2 in the pipe P of the volume $V_{P 1}$. Furthermore, the valve SV6 is closed and the valve SV5 is open. The measuring tube MT is connected in this manner. After opening the valve SV2, the 
compressed oil in the pipe $\mathrm{P}$ expands into the measuring tube MT. During the expansion, the pressure in the steel pipe $\mathrm{P}$ is reduced from the working pressure $p$ to the atmospheric pressure $p_{a}$. The pressure change is hereinafter referred to as $\Delta p$. Furthermore, the oil level in the measuring tube is increased by the value $\Delta h$. The oil volume increase $\Delta V_{P 1}$ is given by the formula:

$$
\Delta V_{P 1}=\frac{\pi \cdot d_{0}^{2} \cdot \Delta h}{4} .
$$

The oil volume in the steel pipe $V_{P}$ at the atmospheric pressure is given by the Eq. (2):

$$
V_{P}=\frac{\pi \cdot d_{P}^{2} \cdot l_{P}}{4}
$$

The volume increase $\Delta V_{P 1}$ at the given pressure gradient $\Delta p$ is directly proportional to the capacity of the oil/pipe system $C_{O, P}$ that is given by the sum of the oil capacity $C_{O}$ and the pipe capacity $C_{P}$ :

$$
C_{O, P}=C_{O}+C_{P}
$$

The oil capacity $C_{O}$, the pipe capacity $C_{P}$ and the capacity of the oil/pipe system $C_{O, P}$ are expressed as follows:

$$
\begin{aligned}
& C_{O}=\frac{V_{P}}{K_{1}}, \\
& C_{P}=\frac{V_{P 1} \cdot d_{P}}{E_{P} \cdot s_{P}}, \\
& C_{O, P}=\frac{\Delta V_{P 1}}{\Delta p} .
\end{aligned}
$$

After substitution of Eqs. (4), (5) and (6) into Eq. (3), the oil bulk modulus $K_{1}$ is expressed by the equation:

$$
K_{1}=\frac{1}{\frac{\Delta V_{P 1}}{V_{P} \cdot \Delta p}-\frac{d_{P}}{E_{P} \cdot s_{P}}} .
$$

The Young's modulus of elasticity of the hose $E_{H 1}$ is further determined. The oil volume increase $\Delta V_{H 1}$ is measured after the oil expansion from the hose. The measurement process is the same as in the case of the measurement of the oil volume increase $\Delta V_{P 1}$ after its expansion from the pipe. The stop valves SV3 and SV4 are used instead of the stop valves SV1 and SV2 in this case. The oil volume increase $\Delta V_{H 1}$ after its expansion from the hose is given by the formula:

$\Delta V_{H 1}=\frac{\pi \cdot d_{0}^{2} \cdot \Delta h}{4}$.

The oil volume in the hose $V_{H}$ at the atmospheric pressure is given by the equation:
$V_{H}=\frac{\pi \cdot d_{H}^{2} \cdot l_{H}}{4}$

The oil volume increase $\Delta V_{H 1}$ at the given pressure gradient $\Delta p$ is directly proportional to the capacity of the oil/hose system $C_{O, H}$ that is given by the sum of the oil capacity $C_{O}$ and the hose capacity $C_{H}$ :

$C_{O, H}=C_{O}+C_{H}$

The oil capacity $C_{O}$, the hose capacity $C_{H}$ and the capacity of the oil/hose system $C_{O, H}$ are expressed as follows:

$$
\begin{aligned}
& C_{O}=\frac{V_{H}}{K_{1}}, \\
& C_{H}=\frac{V_{H} \cdot d_{H}}{E_{H 1} \cdot s_{H}}, \\
& C_{O, H}=\frac{\Delta V_{H 1}}{\Delta p} .
\end{aligned}
$$

After substitution of Eqs. (11), (12) and (13) into Eq. (10), the Young's modulus of elasticity $E_{H 1}$ of the hose is expressed by the equation:

$$
E_{H 1}=\frac{1}{\left(\frac{\Delta V_{H 1}}{V_{H} \cdot \Delta p}-\frac{1}{K_{1}}\right) \cdot \frac{s_{H}}{d_{H}}} .
$$

The values of the oil bulk modulus $K_{1}$ and the Young's modulus of elasticity of the hose $E_{H 1}$ depending on the pressure gradient $\Delta p$ determined by means of the expansion method are shown in Fig. 2.

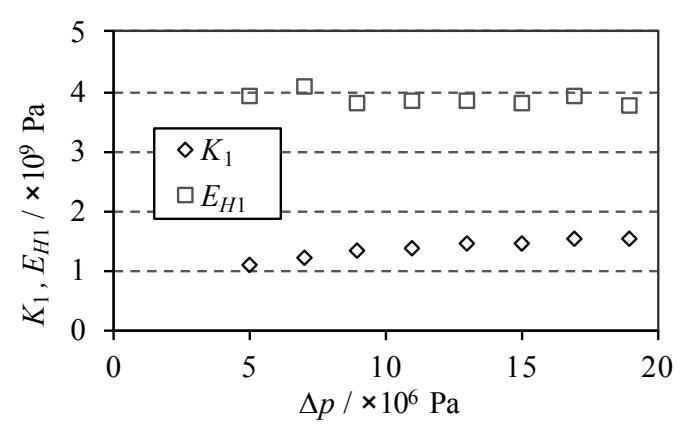

Figure 2 Dependence of oil bulk modulus $K_{1}$ and Young's modulus of elasticity $E_{H 1}$ of hose on pressure gradient $\Delta p$

It is evident (see Fig. 2) that the oil bulk modulus $K_{1}$ is slightly increasing with increasing the pressure gradient $\Delta p$. It is mainly due to compressibility effect of air bubbles that are contained in the oil. The compressibility of air bubbles is decreasing with increasing the pressure [23]. The bubbles are also partially dissolved and the amount of dissolved air is increasing with increasing the pressure $[24,25]$. The oil volume increase $\Delta V_{P 1}$ after the expansion is increasing with increasing the pressure at the expansion method, but the size of this increment decreases. As a result, the oil bulk modulus $K_{1}$ is increasing with increasing the pressure gradient $\Delta p$. At 
the same time, the increase of the oil bulk modulus is decreasing with increasing the pressure gradient.

It is also visible that the Young's modulus of elasticity $E_{H 1}$ of the hydraulic hose remains almost constant $\left(E_{H 1}=3.9 \times 10^{9} \mathrm{~Pa}\right)$ in the measured range of the pressure gradients $\Delta p$. The Young's modulus of elasticity of the hose depends on the inside and outside hose diameters, the number and shape of their braids [26]. The braids are performed in a similar manner as in the case of pneumatic artificial muscles. The increasing internal pressure leads to shortening the length and increase in diameter of the hose due to these braids [27].

\subsection{Determination of oil bulk modulus and Young's modulus of elasticity of hose by means of compression method}

This method for determination of the oil bulk modulus $K_{2}$ and the Young's modulus of elasticity $E_{H 2}$ of the hose consists in measurement of the pressure change $\Delta p$ depending on the time change $\Delta t$ in the pipe $\mathrm{P}$ or the hose $\mathrm{H}$. For this measurement, the hydraulic pump HP was located as close as possible to the steel pipe or the hose in order to minimize the oil volume between the pump and the pipe or the hose. The required working pressure $p=230$ bar was adjusted by the relief valve RV, which is set 40 bar higher than the pressure for which is evaluated the oil bulk modulus $K_{2}$. For this reason, the effect of gradual opening of the relief valve RV on the pressure increase $p$ in the evaluated area $50 \div 190$ bar is minimized. The measurement of the time dependence of the pressure $p$ during the oil compression in the pipe is performed in such a way that the valves SV3, SV4 and SV5 are closed, the valves SV1, SV2 and SV6 are open and the valve $\mathrm{V}$ is set to the position 2 . The valve SV2 is subsequently closed and the oil is compressed in the pipe $\mathrm{P}$ up to the pressure, which is adjusted by the relief valve RV (see Fig. 3). The pressure increase $p$ during the time $t$ is expressed by the secant and the tangent. The secant takes into account the oil compression including air bubbles. The tangent takes into account the oil compression without air bubbles that are already compressed. This tangent corresponds to the area where the pressure increase depending on the time $t$ has an almost linear character.

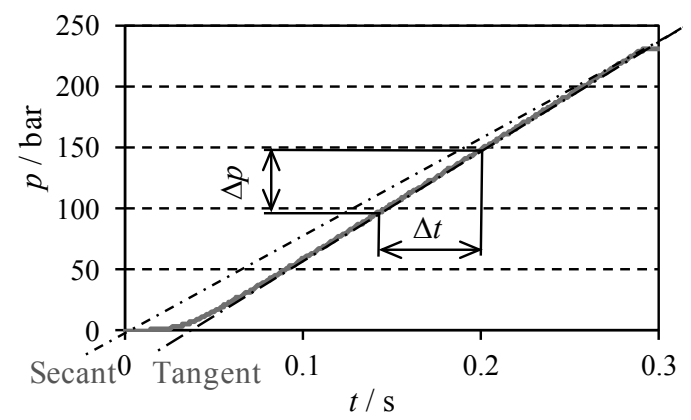

Figure 3 Time dependence of pressure increase $p$ in pipe after closing of valve SV2

The oil bulk modulus, which is determined by the compression method and evaluated from this tangent, is also called the tangent oil bulk modulus. The oil bulk modulus determined from this secant is called the secant oil bulk modulus. The oil bulk modulus, which is determined by the expansion method in the previous chapter, corresponds to the secant bulk modulus.

On the basis of a known $\Delta p-Q$ characteristic of the hydraulic pump HP, it is possible to determine the volume increase $\Delta V_{P 2}$ as follows:

$\Delta V_{P 2}=Q \cdot \Delta t$

The oil volume in the steel pipe $V_{P}$ at the atmospheric pressure is given by the equation:

$V_{P}=\frac{\pi \cdot d_{P}^{2} \cdot l_{P}}{4}$

The oil volume increase $\Delta V_{P 2}$ at the given pressure gradient $\Delta p$ is directly proportional to the capacity of the oil/pipe system $C_{O, P}$ that is given by the sum of the oil capacity $C_{O}$ and the pipe capacity $C_{P}$ :

$C_{O, P}=C_{O}+C_{P}$

The oil capacity $C_{O}$, the pipe capacity $C_{P}$ and the capacity of the oil/pipe system $C_{O, P}$ are expressed as follows:

$$
\begin{aligned}
& C_{O}=\frac{V_{P}}{K_{2}}, \\
& C_{P}=\frac{V_{P} \cdot d_{P}}{E_{P} \cdot s_{P}}, \\
& C_{O, P}=\frac{\Delta V_{P 2}}{\Delta p} .
\end{aligned}
$$

After substitution of Eqs. (18), (19) and (20) into Eq. (17), the oil bulk modulus $K_{2}$ is expressed by the equation:

$$
K_{2}=\frac{1}{\frac{\Delta V_{P 2}}{V_{P} \cdot \Delta p}-\frac{d_{P}}{E_{P} \cdot s_{P}}} .
$$

The Young's modulus of elasticity of the hose $E_{H 2}$ is further determined. Time dependence of the pressure increase in the hose is measured in order to determine this Young's modulus of elasticity. The measurement process is performed in such a way that the stop valves SV1, SV2 and SV5 are closed, the valves SV3, SV4 and SV6 are open and the valve $\mathrm{V}$ is set to the position 2 . The valve SV4 is subsequently closed and the oil is compressed in the hose $H$. Then it is possible to determine the oil volume increase $\Delta V_{H 2}$ by the equation:

$$
\Delta V_{H 2}=Q \cdot \Delta t
$$

The oil volume in the hose $V_{H}$ at the atmospheric pressure is given by the equation:

$V_{H}=\frac{\pi \cdot d_{H}^{2} \cdot l_{H}}{4}$ 
The oil volume increase $\Delta V_{H 2}$ at the given pressure gradient $\Delta p$ is directly proportional to the capacity of the oil/hose system $C_{O, H}$ that is given by the sum of the oil capacity $C_{O}$ and the hose capacity $C_{H}$ :

$$
C_{O, H}=C_{O}+C_{H}
$$

The oil capacity $C_{O}$, the hose capacity $C_{H}$ and the capacity of the oil/hose system $C_{O, H}$ are expressed as follows:

$$
\begin{aligned}
& C_{O}=\frac{V_{H}}{K_{2}}, \\
& C_{H}=\frac{V_{H} \cdot d_{H}}{E_{H 2} \cdot s_{H}}, \\
& C_{O, H}=\frac{\Delta V_{H 2}}{\Delta p} .
\end{aligned}
$$

After substitution of Eqs. (25), (26) and (27) into Eq. (24), the Young's modulus of elasticity $E_{H 2}$ of the hose is expressed by the equation:

$$
E_{H 2}=\frac{1}{\left(\frac{\Delta V_{H 2}}{V_{H} \cdot \Delta p}-\frac{1}{K_{2}}\right) \cdot \frac{s_{H}}{d_{H}}} .
$$

The values of the oil bulk modulus $K_{2}$ and the Young's modulus of elasticity $E_{H 2}$ of the hose depending on the pressure gradient $\Delta p$ determined by the compression method are shown in Fig. 4.

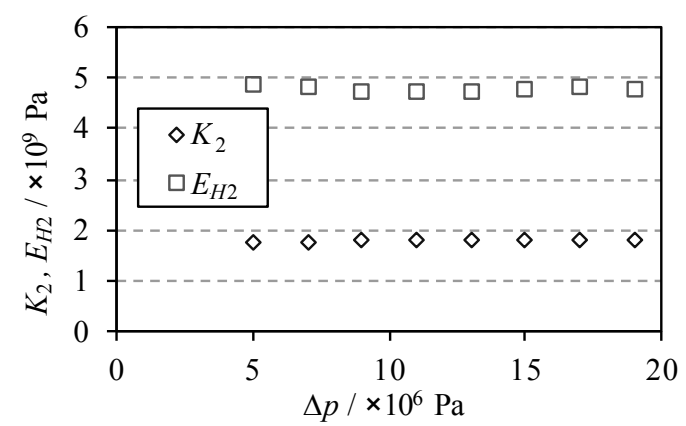

Figure 4 Dependence of oil bulk modulus $K_{2}$ and Young's modulus of elasticity $E_{H 2}$ of hose on pressure gradient $\Delta p$

It is evident (see Fig. 4) that the oil bulk modulus $K_{2}$ remains almost constant in the measured range of the pressure gradients $\Delta p$. The slight increase of the oil bulk modulus $K_{2}$ during the increasing pressure gradient $\Delta p$ is given only by the oil compressibility. Compression of air bubbles at the beginning of the compression process (see Fig. 3) is not included for determining the oil bulk modulus $K_{2}$ by means of the compression method. The oil bulk modulus $K_{2}$ determined by the compression method can be considered as constant $\left(K_{2}=1.79 \times 10^{9} \mathrm{~Pa}\right)$. The oil volume increase $\Delta V_{P 2}$ determined by the compression method is increasing with increasing the pressure. The size of this increase remains almost constant because there is no significant volume change of air bubbles as in the case of the expansion method. The oil bulk modulus determined by means of the compression method is higher than the oil bulk modulus, which was determined by means of the expansion method.

The Young's modulus of elasticity $E_{H 2}$ of the hydraulic hose remains also almost constant $\left(E_{H 2}=\right.$ $\left.4.82 \times 10^{9} \mathrm{~Pa}\right)$ in the measured range of the pressure gradients $\Delta p$. It is evident that the Young's modulus of elasticity $E_{H 2}$ of the hydraulic hose determined by the compression method is about $19 \%$ higher than the Young's modulus of elasticity of the hose $\left(E_{H 1}=3.9 \times 10^{9}\right.$ $\mathrm{Pa})$, which was determined by the expansion method.

As already mentioned, it is necessary to know the experimentally determined oil bulk modulus for the determination of the Young's modulus of elasticity of the hose. The same value of the oil bulk modulus is assumed in the pipe and in the hose. Any difference, which is caused by different amounts of air bubbles in the pipe and in the hose, leads to inaccuracies in determining the Young's modulus of elasticity of the hose by means of the expansion method. It may be a weakness of the expansion method. The mentioned disadvantage of the expansion method is eliminated by the compression method because this method uses the oil bulk modulus, which resembles the value without the content of air bubbles.

The compression method is based on determination of the tangent in the almost linear area (see Fig. 3) during the increase of the pressure $p$ depending on the time $t$. In the case of the steel pipe, the dependence of the pipe stiffness on the pressure is constant. In the case of the hose construction, which resembles a pneumatic artificial muscle, the dependence of the hose stiffness on the pressure is nonlinear, as indicated in [28]. The hose stiffness is lower at the beginning of the oil compression. The hose stiffness increases at higher pressures. It is reflected in the linear increase of the pressure $p$ depending on the time $t$ at the higher pressures. The tangent is subsequently determined for this almost linear area. Then the Young's modulus of elasticity $E_{H 2}$ of the hose determined by the compression method does not include the influence of the nonlinear area of the hose stiffness.

\section{Mathematical model}

A mathematical model of the experimental equipment was created in order to verify the experimentally determined oil bulk modulus $K$ and the Young's modulus of elasticity $E_{H}$ of the hydraulic hose. This mathematical model was created using Matlab SimHydraulics software (see Fig. 5) $[15,29]$. The results of the mathematical models and the experimental measurements are compared. The usability is determined of the oil bulk modulus and the Young's modulus of elasticity of the hose, obtained by means of the expansion method $\left(K_{1}\right.$, $\left.E_{H 1}\right)$ or the compression method $\left(K_{2}, E_{H 2}\right)$.

The hydraulic pump HP is an oil pressure source. Oil flows through the stop valve SV1, the pipe P or the hose $\mathrm{H}$ and the stop valve SV2 into the reservoir R. In the case of closing of the valve SV1 or the valve SV2, the oil flows through the relief valve RV. The circuit also consists of the blocks for valve control (i.e. Control of SV1 and SV2), the block PS1 for pressure measurement, the solver block (i.e. Solver Configuration) and the block for liquid definition (i.e. Oil). The block Time was used in 
order to adjust the scanning time interval $\Delta t=0.001 \mathrm{~s}$ as in the case of the experimental measurements.

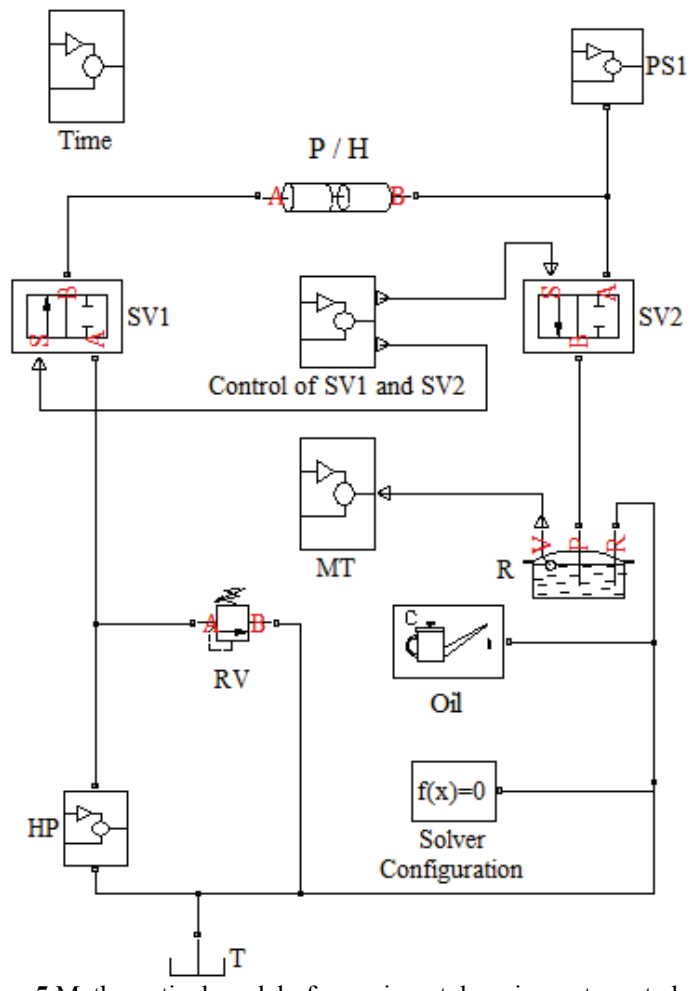

Figure 5 Mathematical model of experimental equipment created using Matlab SimHydraulics software

\section{$4 \quad$ Simulation of oil expansion from pipe}

The simulation of expansion of the compressed oil from the pipe $\mathrm{P}$ was performed by means of the mathematical model (see Fig. 5). The value of the oil volume increase $\Delta V_{P}$ after its expansion from the pipe $\mathrm{P}$ is the result of this simulation. This simulation was performed for two different boundary conditions of the oil bulk modulus. In the case of the simulation of the volume increase $\Delta V_{P 1}$, there was considered the oil bulk modulus $K_{E 1}$ determined from the expansion method in the mathematical model. In the case of the simulation of the volume increase $\Delta V_{P 2}$, there was considered the oil bulk modulus $K_{E 2}$ determined from the compression method in the mathematical model.

The oil flow was defined by means of the block HP in the mathematical model. The pressure gradient was adjusted by the block RV. The pipe $\mathrm{P}$ was pressurized by closing of the valve SV2. The valve SV1 was subsequently closed. The oil under the required pressure is closed in the pipe. Then the valve SV2 is open and the oil expands into the reservoir $\mathrm{R}$, which serves as the graduate. Then the oil volume increase after its expansion $\Delta V_{P 1}$ (or $\left.\Delta V_{P 2}\right)$ is monitored in this graduate.

Elasticity of the pipe or the hose is defined in the mathematical model by means of the coefficient $k_{P}$, which expresses the dependence between the pressure $p$ and the inside diameter of the pipe $d_{P}$ or the hose $d_{H}$. This coefficient for the pipe $\mathrm{P}$ is given by the formula [15]:

$k_{P}=\frac{d_{P}}{E_{P}} \cdot\left(\frac{D_{P}^{2}+d_{P}^{2}}{D_{P}^{2}-d_{P}^{2}}+v_{P}\right)$
The effective oil bulk modulus is defined by means of the block Oil in the mathematical model. This block allows entering the oil bulk modulus as an associated modulus $K_{1}$ in which an undissolved air volume is included. This bulk modulus corresponds to the secant (see Fig. 3) and is experimentally determined by the expansion method (see Chap. 2.2). Then it is necessary to define the appropriate oil bulk modulus $K_{1}$ (see Fig. 2) for each simulated volume increase $\Delta V_{P 1}$ at the given pressure gradient $\Delta p$. In this case the effective oil bulk modulus $K_{E 1}$ is defined by the equation:

$$
K_{E 1}=K_{1}
$$

The effective oil bulk modulus can be further defined by the oil bulk modulus $K_{2}$ without the influence of the undissolved air and by the volume fraction $\alpha$ of the undissolved air. This oil bulk modulus $K_{2}$ without the influence of the undissolved air corresponds to the tangent (see Fig. 3) and is experimentally determined by the compression method (see Chap. 2.3). This oil bulk modulus $K_{2}$ was evaluated as constant in the range of the measured pressure gradients $\Delta p$. The effective oil bulk modulus $K_{E 2}$ is defined in this case by the formula $[9,15$, 30, 31]:

$$
K_{E 2}=K_{2} \cdot \frac{1+\alpha \cdot\left(\frac{p_{a}}{p_{a}+p}\right)^{1 / n}}{1+\alpha \cdot K_{2} \cdot \frac{p_{a}^{1 / n}}{n \cdot\left(p_{a}+p\right)^{(n+1) / n}}},
$$

where $p_{a}$ is atmospheric pressure and $n$ represents polytropic exponent. The simulated oil volume increase $\Delta V_{P 1}$ (or $\Delta V_{P 2}$ ) is subsequently compared with the experimentally measured oil volume increase $\Delta V_{P 1}$ after the expansion depending on the pressure gradient $\Delta p$. The undissolved air content in the oil $\Delta V_{P 2}$ was entered as $\alpha=0.002$ [10].

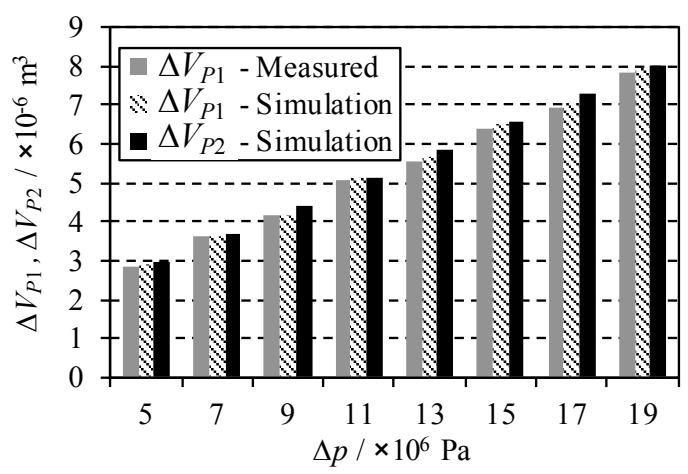

Figure 6 Comparison of simulated and experimentally measured oil volume changes $\Delta V_{P 1}$ and $\Delta V_{P 2}$ after oil expansion from pipe depending on pressure gradient $\Delta p$

There are only slight deviations between the simulated and the measured volume increases after the expansion from the pipe $\mathrm{P}$ for the range of the measured pressures (see Fig. 6). The maximum deviations of the simulated and the measured volume increases were founded for the pressure gradients $\Delta p=9 \mathrm{MPa}$ and 17 $\mathrm{MPa}$, i.e. about $5 \%$. For these simulations, there is not a 
big difference in differently specified boundary conditions for the oil bulk modulus.

The pressure decrease during the oil expansion from the pipe (see Fig. 7) was measured using the experimental equipment. There was performed the simulation of dynamics of the pressure decrease during the expansion. This simulation was performed for the boundary conditions of the oil bulk modulus $K_{E 1}$ and $K_{E 2}$. The Young's modulus of elasticity $E_{P}$ of the pipe was the same for both simulation cases. The effect of opening of the stop valve was taken into account. The opening of the stop valve has an influence on the pressure change in the area $p=140 \div 170$ bar. Further, from the pressure $p=140$ bar, the time dependence of the pressure decrease is mainly influenced by the oil bulk modulus, the undissolved air content, the oil viscosity and the Young's modulus of elasticity of the steel pipe. It is evident from the comparison of the measured and simulated pressure decreases during the oil expansion, that the mathematical model achieves better agreement in the case where the oil bulk modulus is entered as $K_{E 2}$. This is due to the fact that this mathematical model includes the dynamics of the air volume change depending on the pressure. For timedependent simulations, the use of the boundary condition of the oil bulk modulus $K_{E 2}$ is more appropriate in this case.

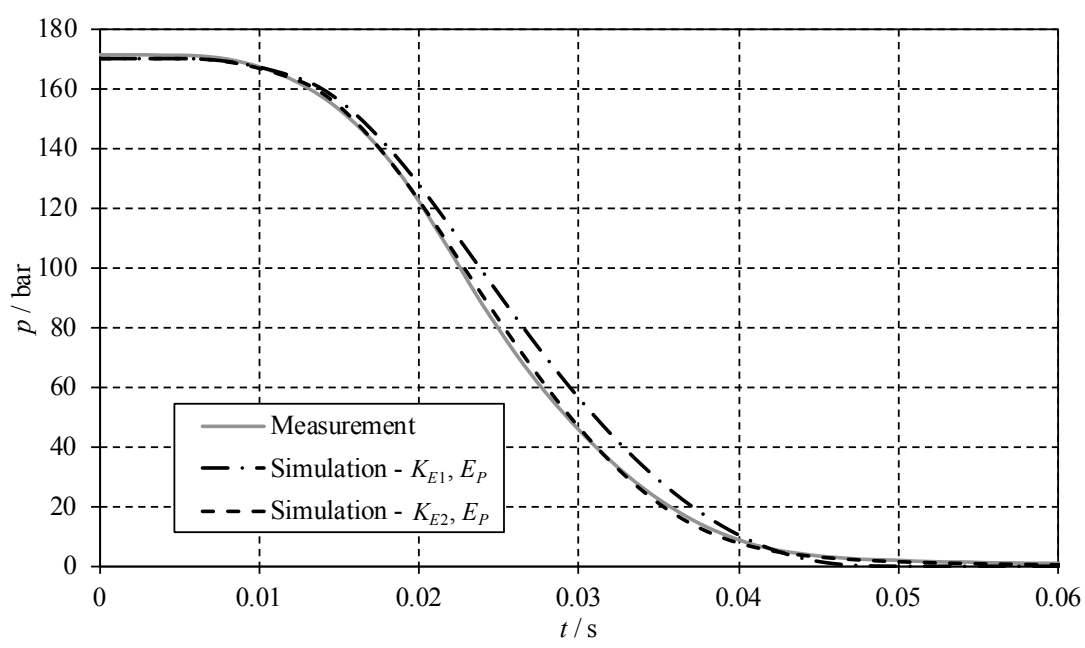

Figure 7 Time dependence of pressure decrease during oil expansion from pipe

\section{Simulation of oil expansion from hose}

The simulation of the expansion of the compressed oil from the hose $\mathrm{H}$ was performed using the mathematical model (see Fig. 5). The result of this simulation is a value of the oil volume increase $\Delta V_{H}$ after its expansion from the hose. This simulation was performed for two different boundary conditions. In the case of the simulation of the volume increase $\Delta V_{H 1}$, there were considered the oil bulk modulus $K_{E 1}$ and the Young's modulus of elasticity of the hose $E_{H 1}$ determined from the expansion method in the mathematical model. In the case of the simulation of the volume increase $\Delta V_{H 2}$, there were considered the oil bulk modulus $K_{E 2}$ and the Young's modulus of elasticity of the hose $E_{H 2}$ determined from the compression method in the mathematical model.

The oil flow was defined by means of the block HP in the mathematical model. The pressure gradient $\Delta p$ was adjusted by the block RV. The pressurization of the hose $\mathrm{H}$ was performed by closing of the valve SV2. The valve SV1 was subsequently closed. The oil under required pressure is closed in the hose. Then the valve SV2 is open and the oil expands into the reservoir R, which serves as the graduate. Then the oil volume increase after its expansion $\Delta V_{H 1}$ (or $\left.\Delta V_{H 2}\right)$ is monitored in this graduate.

The simulated oil volume increase $\Delta V_{H 1}$ (or $\Delta V_{H 2}$ ) is subsequently compared with the experimentally measured oil volume increase $\Delta V_{H 1}$ after the expansion depending on the pressure gradient $\Delta p$. The undissolved air content in the oil for the simulation of the oil volume increase $\Delta V_{H 2}$ was entered as $\alpha=0.002[10]$.

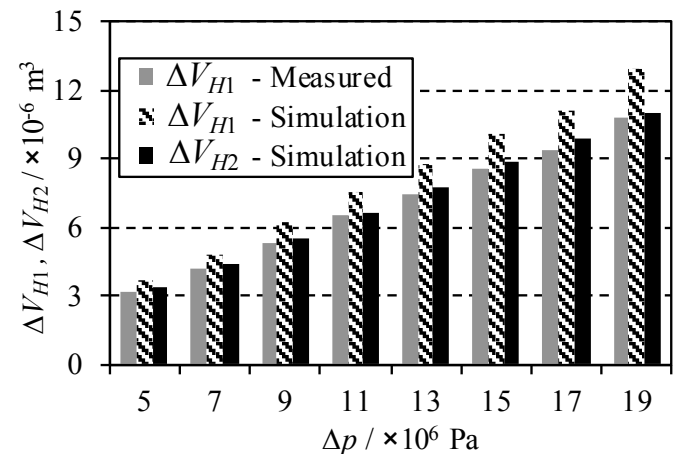

Figure 8 Comparison of simulated and experimentally measured oil volume changes $\Delta V_{H 1}$ and $\Delta V_{H 2}$ after oil expansion from hose depending on pressure gradient $\Delta p$

The differences between the simulations are evident in Fig. 8. The simulation with the boundary conditions $K_{E 2}$ and $E_{H 2}$ corresponds more closely to the experimental measurement of the oil volume increase after the expansion. The deviation from the measured values reached a maximum of about $7 \%$. In the case of the boundary conditions $K_{E 1}$ and $E_{H 1}$, the difference between the measurement and the simulation is up to $20 \%$. This deviation can be caused by an inaccuracy in determination of the Young's modulus of elasticity $E_{H 1}$ of the hydraulic hose by means of the expansion method. For these simulations, it is more appropriate to enter the boundary condition of the Young's modulus of elasticity of the hose, which was measured by means of the compression method (i.e. $E_{H 2}$ ). 
The pressure decrease (see Fig. 9) during the oil expansion from the hose was measured using the experimental equipment. There was performed the simulation of pressure decrease dynamics during the expansion. This simulation was performed for the boundary conditions of the oil bulk modulus $K_{E 1}$ and the Young's modulus of elasticity of the hose $E_{H 1}$. The simulation was subsequently performed for the oil bulk modulus $K_{E 2}$ and the Young's modulus of elasticity of the hose $E_{H 2}$. The effect of opening of the stop valve in the simulation was taken into account. The opening of the stop valve has an influence on the pressure change in the area $p=140 \div 170$ bar. Further, from the pressure $p=140$ bar, the time dependence of the pressure decrease is mainly influenced by the oil bulk modulus, the undissolved air content, the oil viscosity and the Young's modulus of elasticity of the hose. It is evident from the comparison of the measured and simulated pressure decreases during the oil expansion from the hose, that the mathematical model achieves better agreement in the case where the oil bulk modulus is entered as $K_{E 2}$ and the Young's modulus of elasticity of the hose as $E_{H 2}$. This is due to the fact that this mathematical model includes the dynamics of the air volume change depending on the pressure. The Young's modulus of elasticity of the hose $E_{H 2}$ determined from the compression method corresponds more closely to reality, which was also confirmed in the case of the static simulation.

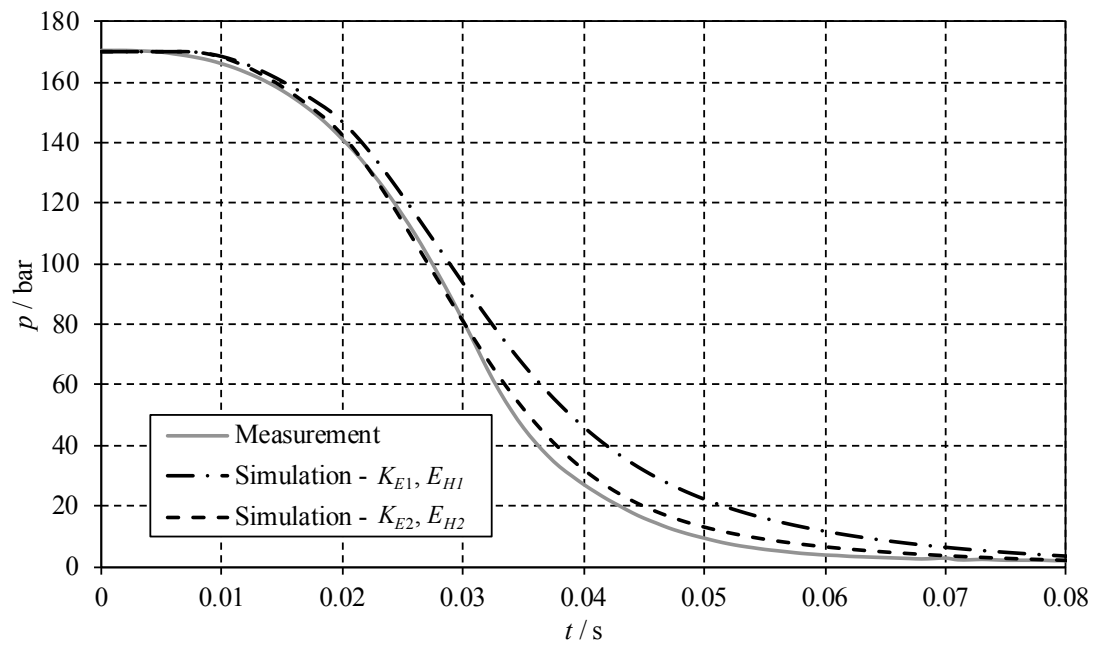

Figure 9 Time dependence of pressure decrease during oil expansion from hose

\section{Conclusion}

The oil bulk modulus and the Young's modulus of elasticity of the hose by means of the expansion method and the compression method were experimentally determined in this paper.

The oil bulk modulus determined using the expansion method increases with increasing the pressure. The oil bulk modulus determined by the compression method is almost constant in the measured range. Furthermore the oil bulk modulus is higher in comparison with the oil bulk modulus, which was determined by the expansion method.

The Young's modulus of elasticity of the hose, which was experimentally determined by the expansion method, is constant depending on the pressure in the measured area. Similarly, the Young's modulus of elasticity of the hose determined by the compression method is also constant depending on the pressure in the measured area. However, its value is greater than the Young's modulus value, which was determined by the expansion method.

In the next section of the paper, the mathematical model of the hydraulic system was created in order to simulate the oil expansion from the hose and the pipe. The oil volume increases were mathematically simulated during the oil expansion from the pipe. Only slight deviations between the simulated and measured oil volume increases were found. Furthermore, the pressure decrease vs. time was mathematically simulated during the oil expansion from the pipe. It is evident from the comparison of time dependencies of the measured and simulated pressure decreases that better agreement was obtained using the oil bulk modulus, which was determined by means of the compression method. In the case of the mathematical simulation of the dynamic processes, it is more appropriate to apply the oil bulk modulus determined by the compression method in this mathematical model.

Subsequently, the oil volume increases were mathematically simulated during the oil expansion from the hose. Furthermore, the pressure decrease vs. time was mathematically simulated during the oil expansion from the hose. It can be concluded on the basis of the obtained results, that it is possible to achieve better results in the case of the hose occurrence in the mathematical model during application of the Young's modulus of elasticity of the hose and the oil bulk modulus that were determined by means of the compression method.

\section{Acknowledgements}

The work presented in this paper was supported by a grant SGS "Research in field of fluid system dynamics" SP2017/103

\section{References}

[1] Cieślik, K.; Lopatka, M. J.; Muszyński, T. Stiffness identification of hydraulic hoses. // $11^{\text {th }}$ International Conference on Intelligent Technologies in Logistics and 
Mechatronics Systems / ITELMS 2016, 28-29 April 2016; Panevezys; Lithuania; pp. 53-59.

[2] Himr, D.; Habán, V. Simulation of low pressure water hammer. $/ / 25^{\text {th }}$ IAHR Symposium on Hydraulic Machinery and Systems,Earth and Environmental Science / September 20-24, Timisoara, Romania, 12(2010), 012087, https://doi.org/10.1088/1755-1315/12/1/012087

[3] Hayward, A. T. J. Compressibility equations for liquids: a comparative study. // British Journal of Applied Physics, 18, 7(1967), pp. 965-977. https://doi.org/10.1088/0508-3443/18/7/312.

[4] Niezrecki, C.; Schueller, J. K.; Balasubramanian, K. Piezoelectric-based Fluid Bulk Modulus Sensor. // Journal of Intelligent Material Systems and Structures. 15(2004), pp. 893-899. https://doi.org/10.1177/1045389X04045151

[5] Wang, J.; Gong, G.; Yang, H. Control of Bulk Modulus of Oil in Hydraulic Systems. // IEEE/ASME International Conference on Advanced Intelligent Mechatronics / Xian, China, July 2-5, 2008, pp. 1390-1395. https://doi.org/10.1109/AIM.2008.4601865

[6] Van de Ven, J. D. On Fluid Compressibility in SwitchMode Hydraulic Circuits - Part II: Experimental Results. // Journal of Dynamic Systems Measurement and ControlTransactions of the ASME 135, 2(2013).

[7] Van de Ven, J. D. On Fluid Compressibility in SwitchMode Hydraulic Circuits -Part I: Modeling and Analysis. // Journal of Dynamic Systems Measurement and ControlTransactions of the ASME 135, 2(2013).

[8] Gholizadeh, H.; Burton, R.; Schoenau, G. Fluid Bulk Modulus: Comparison of Low Pressure Models. // International Journal of Fluid Power. 13, 1(2012), pp. 7-16. https://doi.org/10.1080/14399776.2012.10781042

[9] Jablonská, J. Compressibility of the fluid. // EPJ Web of Conferences 2014 / 67, 02048(2014). https://doi.org/10.1051/epjconf/20146702048

[10] Bureček, A.; Hružík, L.; Vašina, M. Determination of Undissolved Air Content in Oil by Means of a Compression Method. // Strojniski vestnik - Journal of Mechanical Engineering, 61, 7-8(2015), pp. 477-485. https://doi.org/10.5545/sv-jme.2015.2471

[11] Gorgenyi, M.; Dewulf, J.; Van Langenhove, H. Temperature dependence of Henry's law constant in an extended temperature range. // Chemosphere, 48, 7(2002), pp. 757-762, https://doi.org/10.1016/S0045-6535(02)00131-5

[12] Jirouš, S.; Fraňa, K. Pressure Analysis on the Surface Gearing Investigated by Numerical Simulation of Oil Flow in the Tooth Wheel Gap. // Manufacturing Technology, 15, 5(2015), pp. 850-853.

[13] Jablonská, J.; Kozubková, M.; Himr, D.; Weisz, M. Methods of Experimental Investigation of Cavitation in a Convergent-Divergent Nozzle of Rectangular Cross Section. // Measurement Science Review, 16, 4(2016), pp. 197-204. https://doi.org/10.1515/msr-2016-0024

[14] Merritt, H. E. Hydraulic Control Systems. John Wiley \& Sons, New York, 1967, pp. 368.

[15] Matlab SimHydraulics User's Guide, The MathWorks, 2013. http://www.mathworks.com/help/pdf_doc/physmod/ hydro/hydro_ug.pdf.

[16] Nauparac, D. B.; Pršić, D. H.; Miloš, M. V.; Todić, I. S. Different modeling technologies of hydraulic load simulator for thrust vector control actuator. // Technical Gazette. 22, 3(2015), pp. 599-606. https://doi.org/10.17559/TV-20140621063240.

[17] Todić, I.; Miloš, M.; Pavišić. M. Position and speed control of electromechanical actuator for aerospace applications. // Technical Gazette. 20, 5(2013), pp. 853-860.

[18] Detiček, E.; Gubeljak, N.; Kastrevc. M. Design of Lyapunov based nonlinear velocity control of electrohydraulic velocity servo systems. // Technical Gazette. 24, 3(2017), pp. 745-751.
https://doi.org/10.17559/TV-20160930073953.

[19] Soon, C. C.; Ghazali, R.; Jaafar, H. I.; Hussien, S.; Sam, Y. M.; Rahmat, M. F. The effects of parameter variation in open-loop and closed-loop control scheme for an electrohydraulic actuator system. // International Journal of Control and Automation, 9, 11(2016), pp. 283-294. https://doi.org/10.14257/ijca.2016.9.24

[20] Czerwiński, A.; Łuczko, J. Vibrations of steel pipes and flexible hoses induced by periodically variable fluid flow. // Mechanics and Control, [S.1.], 31, 2(2012), pp. 63. https://doi.org/10.7494/mech.2012.31.2.63

[21] Sertić, J. et al. Theoretical determination of elasticity constants for steam boiler membrane wall as the structurally orthotropic plate. // Technical Gazette. 20, 4(2013), pp. 697-703.

[22] Manring, N. D. Hydraulic Control Systems. Wiley, 2005, p. 464.

[23] Gholizadeh, H.; Bitner, D.; Burton, R.; Schoenau, G. Modeling and Experimental Validation of the Effective Bulk Modulus of a Mixture of Hydraulic Oil and Air. // ASME. J. Dyn. Sys., Meas., Control. 136, 5(2014), pp. 051013-051013-14. https://doi.org/10.1115/1.4027173.

[24] Schweitzer, P. H.; Szebehely, V. G. Gas Evolution in Liquids and Cavitation. // Journal of Applied Physics. 21, 12(1950), pp. 1218-1224. https://doi.org/10.1063/1.1699579

[25] Jiang, D.; Li, S.; Zeng, W.; Edge, K. A. Modeling and simulation of low pressure oil-hydraulic pipeline transients. // Computers and Fluids, 67(2012), pp. 79-86. https://doi.org/10.1016/j.compfluid.2012.07.005

[26] Hružík, L.; Bureček, A.; Vašina, M.; Bílek, O. Nondestructive experimental method for determination of modulus of elasticity of hydraulic hoses. // Manufacturing Technology, 15, 3(2015), pp. 344-350.

[27] Sárosi, J. Elimination of the hysteresis effect of pam actuator: modelling and experimental studies. // Technical Gazette. 22, 6(2015), pp. 1489-1494. https://doi.org/10.17559/TV-20140716143627

[28] Focchi, M.; et al. Water/air performance analysis of a fluidic muscle. // 2010 IEEE/RSJ International Conference on Intelligent Robots and Systems / Taipei, 2010, pp. 2194 2199. https://doi.org/10.1109/IROS.2010.5650432

[29] Zhao, Y.; Du, H.; Li, Y.; Luo, X.; Liu, G. Impact of Long Hydraulic Pipeline upon Performance of Hydraulic Control System. // Proceedings of the International Conference of Mechatronics and Materials Processing / Guangzhou, 2011, pp. 2148-2151. https://doi.org/10.4028/www.scientific.net/AMR.328-330.2148

[30] Xu, M.; Ni, J.; Chen, G. Dynamic Simulation of VariableSpeed Valve-Controlled-Motor Drive System with a Power-Assisted Device // Strojniški vestnik - Journal of Mechanical Engineering, 60, 9(2014), pp. 581-591. https://doi.org/10.5545/sv-jme.2013.1532.

[31] Petrović, R.; Živković, M.; Rong, W. Z.; Rakić, D.; Slavković, R. Influence of Air Content Entrained in Fluid of a Vane Pump with Double Effect Operating Parameters. // Technical Gazette, 21, 2(2014), pp. 401-407. 


\section{Authors' addresses}

Lumír Hružik, associate professor

(Corresponding author)

VŠB - Technical University of Ostrava,

Faculty of Mechanical Engineering

17. listopadu 15/2172, 70833 Ostrava-Poruba,

Czech Republic

E-mail: lumir.hruzik@vsb.cz

Adam Bureček, research assistant

VŠB - Technical University of Ostrava

Faculty of Mechanical Engineering

17. listopadu 15/2172, 70833 Ostrava-Poruba,

Czech Republic

E-mail: adam.burecek@vsb.cz

Martin Vašina, associate professor

VŠB - Technical University of Ostrava

Faculty of Mechanical Engineering

17. listopadu 15/2172, 70833 Ostrava-Poruba,

Czech Republic

E-mail: martin.vasina@vsb.cz 